accept only such students as have been selected by severe tests with high standards; it will maintain lofty ideals of knowledge, of observation, of judgment, of original thought and of loyalty. It will uphold these ideals not only by striving to furnish every important material facility in laboratory and hospital, but also by engaging able instructors. The good medical school may become great which adopts as its motto: Great professors make a great school. Let this be your device, for the greater in ideals and achievement your school becomes, the more you will help and inspire all the other medical schools in our country.

Harvard Medical School.

\section{THE SCIENCE OF CLINICAL MEDICINE} WHAT IT OUGHT TO BE AND THE M.EN TO UPHOLD IT *

\section{S. J. MELTZER, M.D., LL.D. NEW YORK}

The honor of the presidency of a society goes with the privilege of discussing some of the aims of that society. Such a privilege becomes a duty on the occasion of its first birthday. We have to show the specificity of our objects to justify the addition of a new medical society to the many already in existence. As your first president and as one of the instigators of the movement which led to the formation of this association permit me to discuss some of the problems to the solution of which this association wishes and hopes to contribute.

\section{CLINICAL MEDICINE AS A SCIENCE}

In the first place, I wish to discuss the problem of clinical medicine as a science. In years gone by, medicine was a unit and its leaders tried to master all its aspects. With the development of scientific methods and the growth of knowledge a process of differentiation took place. Heavy branches grew out of the stem of medicine, broke off and obtained an independent existence. Anatomy with all its dependencies broke away early, then followed physiology, pathologic anatomy, pharmacology and physiologic chemistry. Bacteriology tore off the branches of etiology and established itself as an independent growth. All these offsprings of medicine are now well established as pure sciences; they still closely affiliate with the mother-stem and are often designated as the sciences of medicine. That what is left of the old stem is clinical medicine. What is the character of this residuum? It is generally designated as the practice of medicine. I am not aware that any one has had the courage to call it a pure science. Those who do not like to call it an art say that it is an applied science. According to this view, the relation of clinical medicine to the sciences of medicine is that of technology to science in general. I am afraid that this conception of clinical medicine is widespread among those who are in the practice as well as among those who are in the sciences of medicine.

However this may be, I feel sure that such a view is logically erroneous and practically harmful. I wish to plead for an extension of the process of differentiation also to clinical medicine. I am of the opinion that clinical medicine as it exists now is made up of two constituents: one part has all the elements of a pure science and ought to be coordinate to the other pure sciences of medicine, and the other part is the real practice of

* Presidential address at the frst meeting of the Association for the Advancement of Clinical Research, May 10, 1909, Washington, medicine, an applied science which has many elements of an art. At present both parts are so closely interwoven that they present the appearance of a natural unit the splitting of which into two parts might appear to some as an impossible and undesirable process. I shall call to mind, however, that medicine made the same impression of an indivisible unit in the days when pathologic anatomy, physiology, etc., were inseparable constituents. To-day nobody doubts the necessity of an independent existence for the last-named constituents of former medicine. A considerable degree of separation of the science of clinical medicine from its practice is more desirable than even the separation of the coordinate sciences, because the requirements of sciences and practice are in a certain sense mutually antagonistic to one another and the simultaneous cultivation of both branches with equal attention is detrimental to the progress of either of them.

There is a fundamental difference between science and its correlated practice in any sphere of human activity. Science wishes to attain truthful knowledge of the subject it investigates. It attains this end in the safest way when it is least side-tracked by any extraneous motives. The motive of utility obscures its vision, and haste retards its progress. Practice, on the other hand, avails itself of acquired knowledge for the purpose of attaining a certain useful end. The more reliable that knowledge is which it has to employ, the more safely will it attain that end. But the use of any part of that knowledge which is indifferent to the attainment of the useful end hampers the practical progress. In other words, practice gains its ends best the purer the quality and the smaller the quantity of the science which it has to use. Permit me to say that my advocacy of the separation of a clinical science from its practice is not actuated by any disregard for the practice of medicine. On the contrary, I entertain now and have always entertained a strong conviction that the efficiency of practice should be the supreme object in medicine. At the same time I feel sure that the efficiency of that practice will be best attained when the search for the knowledge which the practice has to use should be carried on in the same manner and by the same methods as are employed in the search for knowledge in other branches of intellectual activity. In other words, clinical research should be raised to a department of a clinical science and be theoretically and practically separated to a considerable degree from the mere practical interests, that is, separated so far as the various and variable conditions permit. It will be the practice not less than the science of medicine which will benefit by such a separation.

Now let us see what the domain of clinical medicine is and whether it contains problems which can be treated by the methods employed in pure science. The sciences of normal anatomy and physiology teach us the structures and functions of the normal body; pathologic anatomy tells us of the anatomic changes found in a body dead from one disease or another. To clinical medicine is left the study of the phenomena and their sequence as they occur in a living body during the entire course of a disease. It has to interpret these phenomena by known physiologic laws, to identify them with similar phenomena experimentally produced in animals and it has to correlate the phenomena observed in the course of a certain disease during life with the anatomic changes found at the postmortem examinations in case the disease has a fatal termination. It is also one 
of the tasks of clinical medicine to study the influence on the onset and course of phenomena of diseases which certain means and remedies may exert whose physiologic actions are well established. In other words, the domain of clinical research comprises the study of the natural history of diseases, their physiology and their pharmacology. Can there be any doubt that these studies constitute legitimate objects of a pure science? Objections may be raised, and will be raised in certain quarters, against the admission of the clinical science to the sacred inner circle of pure sciences on account of the impossibility in clinical medicine to verify the conclusions by the experimental methods. Assuming that this is an unassailable fact, what of it? Are the problems of biology, a science which enjoys an unassailable position in the councils of pure sciences, all or many of them provable by experiment? Or are the sciences of paleontology or geology amenable to an experimental proof? Yet nobody questions the scientific right of these branches of human knowledge. Furthermore, admitting that clinical research must necessarily remain less precise and its results less convincing than that, for instance, of physiology. But, then, physiology itself is again a great deal less precise than physics and chemistry and is certainly less irrefutable than anatomy. Does this throw a doubt on the claim of physiology to be a pure science?

As to the impossibility of verifying certain conclusions regarding human diseases by human experimentation, there is still this much to say. Each disease is an experiment which Nature makes on the organism. The very large number and the great variations of these experiments of Nature offer favorable opportunities for testing the theories made regarding the nature of these spontaneous experiments. Furthermore, clinical research should, indeed, be coupled with animal experimentation; any new point of view gained by observation in clinical medicine which can not be verified on human beings should be tested by experiments on animals. By such a procedure not only clinical medicine, but also physiology may learn a good deal, for which the following facts from the recent history of medicinc are classical illustrations. The recognition of myxedema as a special type of disease led to the understanding of the function of the thyroid glands, and the observation of the coincidence of pathologic processes of the pancreas with diabetes led to the discovery by clinical investigators of the glycolytic function of the pancreas. Finally, it should be borne in mind that there are lines of experimentation which may be carried out even on the sick human being without any detriment to him and which can be conducted with profit only by trained scientific observers, for instance some studies in pharmacology or in metabolism.

Among the tasks of clinical medicine there is one which is on the borderland between the science and practice of medicine, being perhaps of greater importance to the latter than to the former. It is the search for simple or complicated means by which established units of diseases may be recognized safely and perhaps also easily. In one word, it is diagnosis. Since this activity is not carried on with a purpose of adding knowledge, it would appear that it belongs rather to the department of the practice of medicine. Such facts can be established only by means of careful critical observations and it will be more to the purpose when at least the development of the principles of diagnosis should remain in the hands trained in careful methods of research.
After showing that there is a definite field for a science of clinical medicine the next question is who should be the men to carry on the research in this field, what should be their qualifications? In the first place, they must have a training fitting them to carry out investigations in conformity with the requirements existing in all pure sciences. They must not only be informed and trained in the other sciences of medicine, but must have carried on various investigations in one or more of these pure sciences, so as to become familiar with careful scientific methods and imbued with a scientific spirit. 'They will thus learn best how to shape a problem so as to make it amenable to a solution; how to marshall the consecutive steps of an investigation so as to bring out the reply to the question in hand. They will learn to aroid bias in the search, to apply criticism to the findings; they will learn not to trust only few facts, not to rejoice prematurely over findings and not to be disheartened by failures. They will thus acquire the habits and the tastes of the investigator, the scientist, which may then stick to them for life.

However, after all these preparations they must select clinical research as the main field of their scientific activity. Clinical science will not thrive through chance investigations by friendly neighbors from the adjoining practical and scientific domains. Such volunteer service which for the present is keeping up the cultivation of the unacclaimed region is most certainly very welcome. But the acclamation, cultivation and maintenance of a field of pure science of clinical medicine can not be accomplished by chance services from volunteers; for such a purpose we need the service of a standing army of regulars. The investigator in clinical science must devote the best part of his time and intellectual energies to the cultivation and elevation of this field just as the the physiologist does in his domain - or at least as he ought to do. For the sake of elucidation let us compare the relations of a science of clinical medicine to its practice with the relations of science to technology in any part of physics or chemistry. Let us take electricity as an instance. In the electrical industry there is a large corps of electrical engineers who are bright, inventive and on the alert to make practical use of any newly discovered principle in general. Some practical engineers manage to make valuable contributions to the theoretical knowledge of their branch. Nevertheless the science of electricity is in the hands of pure scientists who are setting the pace of progress in the correlated practical branch. It is the discovery in pure science which makes great inventions possible. It was, for instance, the purely scientific demonstration by Hertz of the existence of electric waves that gave the impetus to and made the invention of wireless telegraphy possible. The following is a quotation from the presidential address of Professor Nichols before the Association for Advancement of Science ${ }^{1}$ : "Communities having the most thorough fundamental knowledge of pure science will show the greatest output of really practical inventions." This is surely true also for medicine. And let me say to you that the Hertz's, the Roentgens, the Bunsens, the Emil Fischers, and a host of others, who are the real creators of knowledge and invention, are satisfied to live on comparatively small salaries, while it is within their easy reach to make twenty times the amount of their salaries as consultants, if they would be willing to give up a part of their time which they devote to inves-

\footnotetext{
1. Scrence, Jan. 1, 1909, p. 5 .
} 
tigations in pure science. Now, the leaders in practical engineering in electricity surely compare favorably with the leaders in the practice of medicine with regard to the completeness of their knowledge in the respective spheres. While thus the search for knowledge in electricity is carried on by men devoting themselves to pure science, the search for knowledge in clinical medicine is left in the hands of men who devote most of their time and energies to their practice and to the golden fruit it bears. Under such circumstances, how shall we expect to find the progress in science and practice of medicine keeping abreast with the striking progress to be met with in other branches of science and practice?

A few years ago $I$ tried to fix the responsibility for the shortcoming of internal medicine in physiology, because this science is keeping aloof from medicine and its problems. $^{2}$ Anatomy, which gave its undivided attention to the human structures, prepared an excellent basis for a successful surgery, the problems of which are essentially mechanical in character. The problems of clinical medicine are essentially of a functional character, and the enlightenment which it requires must come from physiology. This science, however, developed a tendency to keep at a distance from medicine on account of the inexactness of the latter. There is an improvement to be noted in this regard; there is a growing tendency in physiology nowadays to pay greater attention to medical problems. However, even if physiology and other related medical sciences would devote all their time and energy to the study of purely medical problems, it would not bring about a radical solution of our perplexing problem. Neither will this be accomplished by the creation of chairs for experimental medicine. The regeneration or rathe: creation of a science of clinical medicine must come from the innermost of medicine itself. It is true, as stated before, that the men who are to tackle these problems must have a thorough training in the sciences allied to medicine, but the center of their activities must be within clinical medicine itself. They must have a bringing up within medicine, their minds must have been filled up with thinking, worrying, brooding over practical and theoretical problems of clinical medicine.

Let me recapitulate. There is a necessity for a differentiation of clinical medicine into a science and a practice. The clinical science has well-defined objects and is a most important department. It must be managed by a set of men specially trained for and almost exclusively devoted to that task. Without the development of such a department of clinical science the efficiency of the practice of internal medicine will lag behind, no matter how progressive the allied sciences of medicine are and how great their efforts to be useful to medicine may be.

\section{THE CONDITIONS AS THEY ACTUALLY EXIST}

In conjunction with the foregoing considerations let me glance at the conditions of clinical medicine as they actually exist here and abroad. I may state that neither abroad nor here do we find a separate class of investigators confining their activity solely to the domain of the science of clinical medicine. Everywhere science and practice of clinical medicine go hand in hand. We may, however, admit at the outset that there is an enormous difference in the status of medical research between abroad and here. Let us take the development 2.

2. Congress of Science and Art, 1904, v, 395; chairman's ad- and the present status of clinical medicine of the German-speaking countries as an illustration of the conditions abroad. We shall notice that there the mother stem of medicine managed to retain a scientific aspect despite all processes of differentiation.

When for the first time pathologic anatomy broke away completely from medicine and was taught by Rokitansky at the University of Vienna as an independent branch of medical science, we find that at the same time and at the same place the celebrated Skoda was teaching the remaining trunk of clinical medicine as a natural science, constructing the methods of auscultation and percussion on a sound basis and establishing a firm connection between the intravitam diagnosis and the postmortem findings. The purely anatomic tendencies of that celebrated school of medicine which unfortunately gave birth to nihilism in medicine, was soon curbed by the appearance of Virchow on the medical scene in Berlin. While also working for the establishment of pathologic anatomy, gross and histologic, as an independent natural science, he manifested throughout his long life a deep interest in the development of clinical medicine on sound lines. At the very beginning of his brilliant career we find him stating (in the prospectus to the first volume of his Archiv) that practice of medicine should be an applied science and the ideal of the science should be a complete pathologic physiology. The great clinical contemporaries of Virchow strove for a similar ideal. Frerichs introduced chemistry and Ludwig Traube the methods of experimental physiology into the domain of clinical medicine. I shall not dwell here further on historical details. I shall only say that clinical medicine in Germany remained true to this ideal throughout all these years of marvelous growth of medicine. The exponents of clinical medicine in Germany are the flag bearers of pathologic physiology. The contemporary clinicians master the immense knowledge and manual skill which contemporary clinical medicine demands of its disciples, and nearly all of them are themselves diligently adding new facts to the store of medical science. I do not need to tell you the particulars. Some of you know from personal experience such master clinicians like Müller, Krehl, Kraus, Minkowsky, and a good many others like them. However, the standard of medicine is kept high not only by the heads of university clinics; the various members of their staffs, heads of hospitals and their staffs and a host of volunteer workers are continually digging for new fruit in the soil of clinical medicine. The medical literature is full of original, first-rate work in the science of clinical as well as of experimental medicine contributed by men whose main abode is clinical medicine.

Now there is in Germany no special chair for the science of clinical or even experimental medicine. All these contributors to medical science are in a sense simply medical practitioners. What is the secret of their scientific success? It is simply this: to these men science is the first and practice the second object of their life. To most of the leaders of medicine in Germany the tasks of gaining and diffusing knowledge receives their first attention and the consultation practice comes in last. Again, these very leaders before they have acquired their commanding positions spent many years of their life in preparing themselves for it; in training in scientic methods, in acquiring knowledge in the allied sciences and in the science and practice of clinical medi. cine, living meanwhile on small incomes, having no pri- 
vate practice at all or having a practice too small to interfere with their life ambition. You can not lead such a life unless you are possessed by idealism and a scientific spirit. That is the key to their success. And when these men become teachers, they can not fail to impart this ideal spirit to their atudents. That is the way they themselves received it. But they received it also in the institutions of their early education, where sport and habits of millionaires' sons are not the factors which form the character of the youth. They received it from the people among whom they grew up, among whom the worth of the individual is not measured exclusively by a gold standard. They received it from the care and encouragement of the government which, no matter what its political ideals may be, never loses sight of the fact that the cultivation of science is one of the greatest assets of a people. They received it in the traditions of medicine of their country; even before the new era when medicine was all in a cloud of so-called natural philosoply, only the substance of medicine was all wrong, its spirit was all right.

That is the situation abroad. Now let us look at the development and the present status of clinical medicine in this country. At a glance one observes with amazement that nearly all the factors which favored the derelopment of a scientfiic spirit in Germany are absent. However, I shall not try to enumerate all the shortcomings with which the development of medicine in this country had and still has to contend. There is no educational advantage in doing it and you are all familiar with the situation. On the contrary, I take pleasure in pointing out the encouraging fact that, despite all the difficulties, medicine in this country gradually rose to a commanding position in many respects. It is an instructive and stimulating fact that the progress of medicine in this country was carried on through the efforts of a few high-minded men or groups of men who at various times transplanted the spirit prevailing abroad into this country. I shall, of course, not attempt to enter into the particulars of the history of this progress. I wish to refer briefly, however, to a few phases in this history. In the first important phase. clinical medicine in America received an elevating impulse through the activities of a group of medical men who continued their studies in France, where they came especially under the influence of the famous clinician Touis. Statistical methods of observation of diseases and diagnosis bv auscultation and percussion became, then, the chief characteristics of internal medicine in this country. During the second period, young American physicians pursued their postgraduate studies in Austria and Germany. They brought home a knowledge of gross and minute pathologic anatomy and an aptitude for the use of the microscope. Pathologic societies were started and the teachers of medicine began to give separate lectures on pathologic anatomy and to instruct in the use of the microscope as a clinical aid. The studies and teaching of these new subjects gave at that time a scientific flavor to clinical medicine. The last period covers about the three last decades with the contradictory results of which we are confronted to-day. Again, medical men went abroad for postgraduate studies and perhaps in larger numbers than ever. But what this high class of young medical men studied there now was no longer in the direct interest of clinical medicine; they trained themselves in the intricacies of the sciences of medicine. The results of the studies of this period were again of great benefit to medicine in this coustry; in fact, they were of greater benefit than ever. In a comparatively short period the special sciences of medicine, thanks to the activity of a brilliant group of men, have gained a strong foothold in this country; special chairs and laboratories were created in many schools of medicine for pathology, physiology, bacteriology, pharmacology and physiologic chemistry. The work which is being accomplished now in these laboratories compares favorably with the work done in the countries with older scientific traditions and much more favorable surroundings. However, by this very departure clinical medicine itself suffered a visible retardation in the development of its own department. I discuss this phase not with pleasure, but the truth must be said. To my mind it is a fact that the leading clinicians of this generation do not compare favorably with their predecessors in this country, not to speak of a comparison with the leaders of clinical medicine in other countries. One of the reasons for the retardation in the progress is the loss to clinical medicine of the brainy men who now devote their energies to the pure sciences of medicine. Another reason may be found in the fact that by giving up pathologic anatomy and microscopy to special departments clinical medicine lost that part which has given it formerly its scientific character. An evident drawback to the progress of internal medicine in this country is the fact that its teaching at the present time is mostly still in the hands of men who received their medical training nearly exclusively in this country and at a time when pathologic anatomy was the exclusive basis and auscultation and percussion practically the exclusive methods of diagnosis. But in the last twenty-five years internal medicine changed its aspect greatly. The men who want to teach the medicine of to-day must have an education and training radically different from those which were customary and sufficient in former years.

However, the greatest evil of them all is the deplorable fact that in most instances internal medicine is taught in this country by very busy consultants who can give only a small fraction of their time and mental energy to this one of the side issues of their busy lives. Teaching medicine and furthering its science is a very serious business which ought to be carried on by men who are ready to devote all or most of their time to it.

Here are problems for you to solve. The progress of clinical medicine in this country has to be accelerated again. We might reach the level which we have seen to exist abroad. But we ought to strive to get still higher; in this field lack of modesty is a stimulating virtue. Look at the allied sciences of medicine, the level of which they have reached in a comparatively short time without any tradition and only through the activity of a small group of high-minded men. The progress of medicine in this country was always carried on by the few and not by the masses. Clinical medicine must reclaim some of the brainy young men who were enticed by the sciences of medicine. You represent a new generation. You have had an education and a training in modern medicine and the allied sciences. You have a training in investigation, the constitution requires it of you. The constitution which you have adopted shows your spirit. Among its objects is "the cultivation of clinical research by the methods of the natural sciences and the diffusion of a scientific spirit among its members." But you will accomplish more; the constitution imposes on you the obligation to be active in the diffusion of the principles of the society particularly among the students who come under your charge. I would recall this obliga- 
tion to the minds of the members who were called within this year to chairs of medicine at influential places. The constitution does not keep you down exclusively to science, but let me tell you: beware of practice. It is a bewitching graveyard in which many a brain has been buried alive with no other compensation than a gilded tombstone.,

One last word. The men whom you now see sitting on the bank left behind while the boat of progress swiftly glides away with fresh winds and under fresh sails were themselves in their youth passengers of similar boats and cut faces at others who were left behind. Be generous to them, but do not repeat their mistakes. The secret is: never leave the boat.

Rockefeller Institute for Medical Research.

\section{Original Articles}

\section{THE NEED, METHODS AND VALUE OF MEDICAL COLILEGE INSPECTION*}

\author{
N. P. COLWELL, M.D.
}

Secretary of the Council on Medical Education, of the American Medical Association CHICAGO

That we have in this country no national body having legal power to charter and control educational institutions is generally understood. Under our system of government this control, along with the licensing of physicians, belongs to the police powers of the various states. In the majority of foreign countries, however, there are national boards or committees which charter all schools, including medical, and which insist on definite standards being maintained.

This country is still comparatively young and in some respects has not attained full growth. Our educational institutions have been allowed to shift for themselves and, of course, much confusion of standards has resulted. The past eight or ten years, however, has seen a gradual development toward system and in the last few years particularly rapid progress has been made. At the present time only three or four states regulate the chartering of institutions, while in the majority of states any body of men can secure articles of incorporation for a college or school by paying the required fee, no question being raised regarding the ability of the incorporators to furnish education.

As might be expected, we have, taking the country as a whole, a large number of educational institutionsincluding medical colleges-with a great variety of methods and standards. We find some high schools and academies attempting to teach college subjects to students from the elementary grades and, worse still, we also have so-called colleges and universities teaching high school subjects and granting baccalaureate degrees on that basis.

\section{VARIETY OF "MEDICAL COLLEGES"}

When we come to the institutions professing to teach medicine in whole or in part, we find even greater confusion. From the various healing cults which have no use for the fundamental principles of medical science up to the thoroughly equipped, high-grade university medical schools-and all must be included in any complete investigation of medical education-this country

* Read before the Nineteenth Annual Convention of the National Confederation of State Medical Examining and Licensing Boards, Atlantic City, N. J., June 7, 1909. has more medical schools than all the rest of the world combined and, on the whole, lower standards than are to be found in any other country.

The medical cults referred to have practically no standards or, at best, enforce only a common school education for admission and give a two or three year course, after which they turn out "doctors" of this, that, or the other-it does not matter to the average layman who doesn't know the difference. But even among the schools usually included in the term "medical colleges" there is a most amazing variety of standards. There are several, the entire equipment of which consists of a blackboard, a table and some chairs. There are some which merely drill their students in answering questions asked at state board examinations, having no use for laboratories and clinics. Meanwhile the graduates of these schools usually succeed in passing the state license examinations. There are colleges which grant the degree after a course given in the $21 / 2$ or 3 hours at night for four years of 30 or 40 weeks each, which, to equal the actual time spent by students in our day schools, would require from 12 to 14 years. There are still colleges at which ungraded courses of lectures are given year after year to all classes alike. There are legally chartered medical colleges located in towns so small as to make clinical material seriously limited or entirely lacking. There are several at which no clinical training in obstetrics is given and more at which no postmortems are seen by the students and where there is no opportunity to study gross pathologic specimens. On the other hand, there are numerous grades of institutions up to the small but increasing number of high grade medical colleges which are probably equal to any in the world.

I have given only a brief statement of the amazing variety of institutions professing to teach medical students and which are annually turning out armies of those who seek the privilege of practicing medicine. While many are thoroughly competent, there are, doubtless, many who are illiterate, untrained and decidedly incompetent. While they differ greatly in their educational qualifications and possibly in their "methods of treatment," those who, by whatever hook or crook, secure the right to practice will be alike in this respect: they. will all be required to differentiate between health and disease, to determine the nature of diseases, deformities and injuries, and to stand between life and death in many of the cases to which they may be called.

\section{IMPORTANCE OF STATE BOARDS}

Under our form of government, the only legal barrier which stands between a sick and suffering humanity and this job-lot of would-be practitioners is the state licensing board. How important it is, therefore, that the state board be given full power, and that all obstacles be removed from its path. The splendid work that has been done by these boards, often in spite of many difficulties, is the most hopeful sign that this problem will, in time, be properly solved.

At the present time, however, too many obstacles are hindering the boards from obtaining the best results. There are now some 65 or more boards in the 50 states, only a few of which are given sufficient financial support to permit of the best work, and many are continually having to contend with the inconsistencies of legislatures, which, after adopting strong medical practice acts, containing fair educational standards, proceed to limit seriously the board's power by granting special legislation to this, that or the other medical sect, providing for special standards or special boards. It has been 